\title{
A coal miner with weakness, fatigue, nausea, fever, chills, night sweats and dyspnea
}

Larry Nichols MD ${ }^{1}$

Author Affiliations:

1. Mercer University School of Medicine, Macon, Georgia

The author has no financial disclosures to declare and no conflicts of interest to report.

\section{Corresponding Author:}

Larry Nichols MD

Mercer University School of Medicine

Macon, Georgia

Email: Nichols_1@mercer.edu 


\section{Abstract}

Delayed or missed diagnoses are a constant hazard in primary care. This is the case report of a 51-year-old coal miner, who presented on a Friday as an ambulatory outpatient with weakness, fatigue, nausea, fever, chills, night sweats and dyspnea. Chest x-ray on Saturday showed pneumonia and pleural effusion, while blood testing showed renal failure, but these results were not known by his physician until Monday, when he was hospitalized with severe sepsis due to fatal Austrian syndrome of pneumococcal pneumonia, endocarditis and meningitis. Analysis of the delay of diagnosis in this case suggests the possibility that a weekend effect of presentation as an ambulatory outpatient on a Friday may be a source of diagnostic error in primary care.

\section{Keywords}

Austrian syndrome, diagnostic error, patient safety, primary care, weekend effect

\section{Introduction}

Delayed or missed diagnoses are a constant hazard in primary care. ${ }^{1}$ Diagnostic errors of this type affect at least $5 \%$ of US adults (12 million) every year. ${ }^{2}$ Pneumonia, heart failure, and renal failure were the three most common delayed or missed diagnoses, attributed to errors in diagnostic test ordering (in 57.4\% of cases), cognitive errors in taking the medical history (in $56.3 \%$ ) and physical examination (in $47.4 \%$ ), often multifactorial, in one study. ${ }^{3}$ In another study, multiple symptoms or co-morbidities masking the real problem was the third most common clinician-identified problem leading to delayed diagnosis. ${ }^{4}$ Communication problems related to diagnostic testing may account for nearly half of all errors in typical primary care practice. ${ }^{5}$ Learning from missed opportunities for diagnosis is essential for improving patient safety. ${ }^{6}$ The following case is reported for its potential contribution to learning.

\section{Case Report}

This 51-year-old white male coal miner from a small town in rural Appalachia saw his primary care physician for the first time in five years on a Friday in October. He presented with progressive weakness, generalized fatigue and decreased appetite for six to eight weeks. This was associated with nausea for one to two weeks, but no vomiting or diarrhea. He had been having fevers, chills and night sweats for several months. He also had dyspnea on exertion. He had been not feeling well, "not doing well". He had seen several doctors and had had numerous tests, with no apparent diagnostic resolution. He had been taking ibuprofen, tramadol, tizanidine and benzonatate. 
The patient had a history of gastroesophageal reflux disease. He had a history of smoking one pack/day for fifteen to twenty years before quitting twenty years ago and drank approximately three to four beers per day. The patient had been a coal miner for thirty two years, but had gone on workman's compensation after sustaining back, neck and right shoulder injuries, lifting heavy objects at work three months prior. The patient and his wife were working on the assumption that his illness was work-related and he no doubt conveyed this impression to his physician. His weight was 168 pounds, from 181 pounds five years prior. Blood tests and chest $\mathrm{x}$-ray were ordered.

On Saturday, blood testing was done, but the results were not seen by his primary care physician. Also on Saturday, a chest radiograph was performed, but not interpreted. On the night of Sunday, the patient became more short of breath and listless, with fever and chills.

On Monday, the patient was found unresponsive by his wife and was brought to a hospital emergency department. On arrival in the emergency department at 08:51, his temperature was $97^{\circ} \mathrm{F}$, heart rate $107 /$ minute, blood pressure $186 / 67 \mathrm{~mm} \mathrm{Hg}$, respirations $20 /$ minute and saturation $100 \%$ on supplemental oxygen via non-rebreather mask. He was unresponsive. He had decreased breath sounds on the left and pulmonary rhonchi and crackles on the right. The patient was intubated and put on mechanical ventilation at 08:55. Blood drawn at 08:40 showed: creatinine $3.73 \mathrm{mg} / \mathrm{dL}$, urea nitrogen $51 \mathrm{mg} / \mathrm{dL}$, sodium $131 \mathrm{mEq} / \mathrm{L}$, potassium $4.1 \mathrm{mEq} / \mathrm{L}$, chloride $95 \mathrm{mEq} / \mathrm{L}$, carbon dioxide $16 \mathrm{mEq} / \mathrm{L}$, glucose $131 \mathrm{mg} / \mathrm{dL}$, white blood cell count 20,500/cu mm (94.3\% granulocytes, $3.1 \%$ lymphocytes, $2.2 \%$ monocytes), hemoglobin $7.1 \mathrm{~g} / \mathrm{dL}$, platelets $605,000 / \mathrm{cu} \mathrm{mm}$, international normalized ratio (INR) 1.1, B-type natriuretic peptide (BNP) $12,915 \mathrm{pg} / \mathrm{mL}$, and troponin $<0.04 \mathrm{ng} / \mathrm{mL}$. Arterial blood drawn at 08:55 showed: $\mathrm{pH}$ 7.19, pCO2 $43 \mathrm{~mm} \mathrm{Hg}, \mathrm{pO} 280 \mathrm{~mm} \mathrm{Hg}$ and bicarbonate $16.4 \mathrm{mEq} / \mathrm{L}$, on mechanical ventilation with $80 \%$ oxygen and positive end-expiratory pressure (PEEP) of $5 \mathrm{~cm} \mathrm{H}_{2} \mathrm{O}$.

Chest radiograph from Saturday was signed out showing left lower lobe infiltrate with air bronchograms and a small pleural effusion with compressive atelectasis. New chest $\mathrm{x}$-ray showed worsening left lower lobe airspace disease with increasing left pleural effusion (compared to Saturday). Electrocardiogram at 10:35 showed first degree AV block, QTc $483 \mathrm{~ms}$ and nonspecific ST abnormality. At 10:45, the patient's heart rate was 109/minute, blood pressure 126/62 $\mathrm{mm} \mathrm{Hg}$, respirations 23/minute and he was given ceftriaxone.

On admission to an intensive care unit at 11:00, the heart rate was 102/minute, blood pressure $135 / 68 \mathrm{~mm} \mathrm{Hg}$, respirations 23/minute and saturation 100\%. Ultrasound examination of the kidneys showed mild hydronephrosis and increased cortical echogenicity consistent with medical renal disease. At 13:25 the patient's temperature rose to $101.7^{\circ} \mathrm{C}$. Left thoracentesis was performed at 14:30 with removal of $1650 \mathrm{~mL}$ of cloudy pleuritic fluid with a slight green tinge. Bronchoscopy at 14:45 showed purulent secretions in the bronchi. Gram stain of left pleural 
fluid showed many white blood cells and many Gram-positive cocci in chains. Gram stain of left bronchial washing showed many white blood cells and rare Gram-positive cocci.

Arterial blood drawn at 14:50 showed pH 7.33, pCO2 $36 \mathrm{~mm} \mathrm{Hg}, \mathrm{pO} 281 \mathrm{~mm} \mathrm{Hg}$ and bicarbonate $19 \mathrm{mEq} / \mathrm{L}$ on $50 \%$ oxygen. At 16:40 the patient's blood pressure fell to $97 / 44 \mathrm{~mm}$ Hg. At 16:54, his temperature was $100.2^{\circ} \mathrm{C}$, heart rate $120 /$ minute, blood pressure $81 / 43 \mathrm{~mm}$ $\mathrm{Hg}$, respirations 30/minute and transfusion of a unit of red blood cells was started. His clinical condition deteriorated, with ventricular tachycardia, then atrial fibrillation with a rapid ventricular response, and then he lost his pulse at 17:30. The patient was resuscitated once, but arrested again. This time, he failed to respond and he died at 18:50.

The blood tests from Saturday had shown a white blood cell count of 15,000/cu mm, hemoglobin $6.7 \mathrm{~g} / \mathrm{dL}$, creatinine $3.37 \mathrm{mg} / \mathrm{dL}$, sodium $128 \mathrm{mEq} / \mathrm{L}$, potassium $4.2 \mathrm{mEq} / \mathrm{L}$, chloride $95 \mathrm{mEq} / \mathrm{L}$, carbon dioxide $22 \mathrm{mEq} / \mathrm{L}$, and albumin $1.8 \mathrm{~g} / \mathrm{dL}$.

Following his death, echocardiogram was reported showing severe aortic regurgitation with a vegetation of the right coronary cusp, aortic root dilated to $4.1 \mathrm{~cm}$, and mild prolapse of the mitral valve anterior leaflet, along with a mildly dilated left ventricle with mild concentric hypertrophy and an ejection fraction of $>55 \%$, trace mitral regurgitation, and a small generalized pericardial effusion. Left bronchial washing culture yielded normal flora. Left thoracentesis fluid culture yielded alpha-hemolytic Streptococcus.

Autopsy revealed bacterial endocarditis, with large aortic valve vegetations on each cusp up to 3 $\mathrm{cm}$ (Figure 1), with numerous bacterial cocci. Postmortem examination also demonstrated severe acute left lower lobe pneumonia, left-sided empyema (Figure 2) and widespread acute meningitis. The kidneys had severe necrotizing glomerulonephritis. 
Figure 1. Aortic valve vegetations at autopsy, 3 x $1.5 \times 0.6 \mathrm{~cm}$ on right coronary cusp, $2.4 \times 1.6 \mathrm{x}$ $1.1 \mathrm{~cm}$ on non-coronary cusp, and $0.7 \times 0.3 \times 0.2 \mathrm{~cm}$ on left coronary cusp.

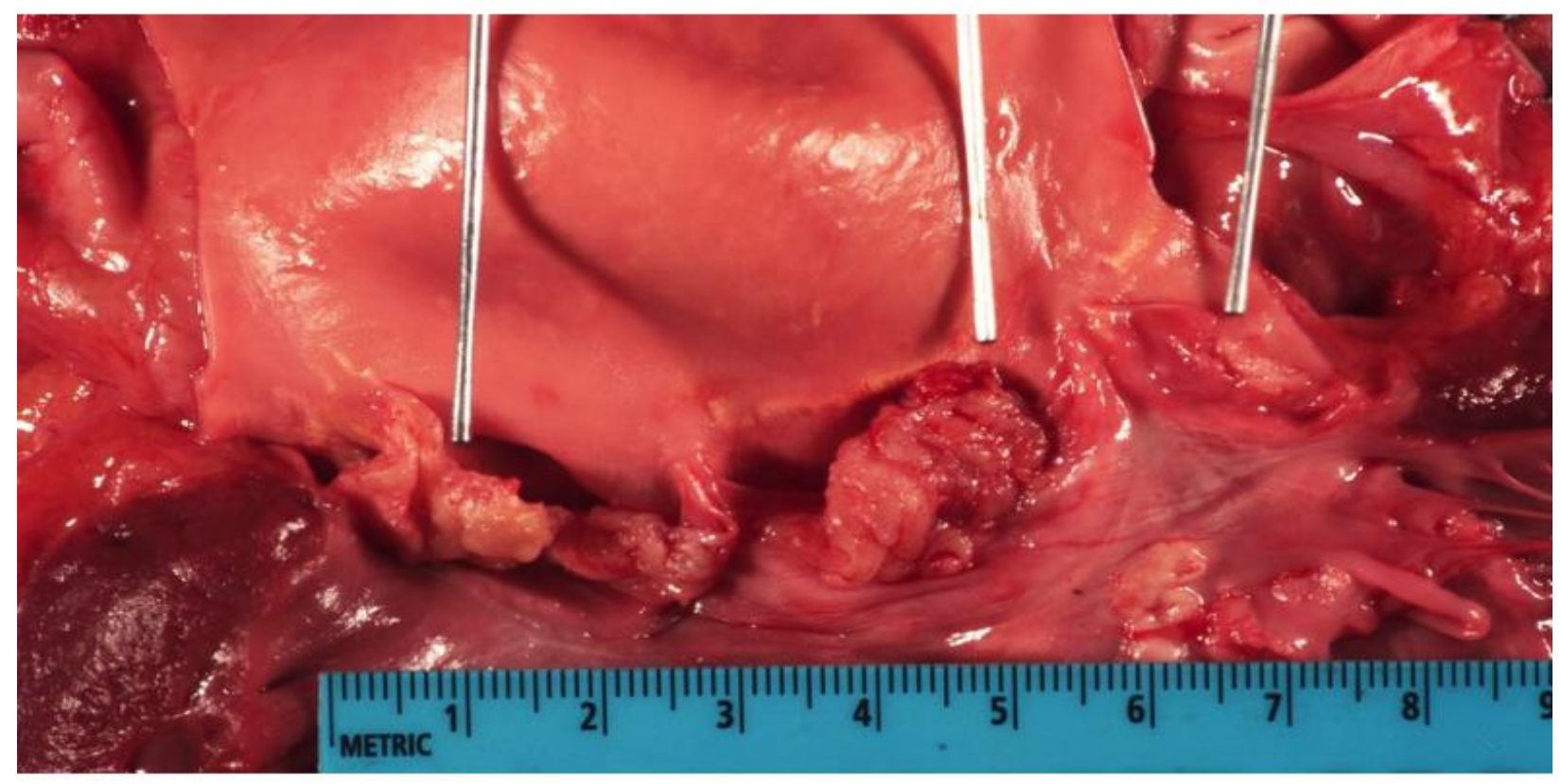

Figure 2. Fibrinopurulent exudate over approximately $80 \%$ of left lower lobe and $60 \%$ of upper lobe at autopsy following drainage of $1650 \mathrm{~mL}$ of empyema 4 hours 20 minutes antemortem.

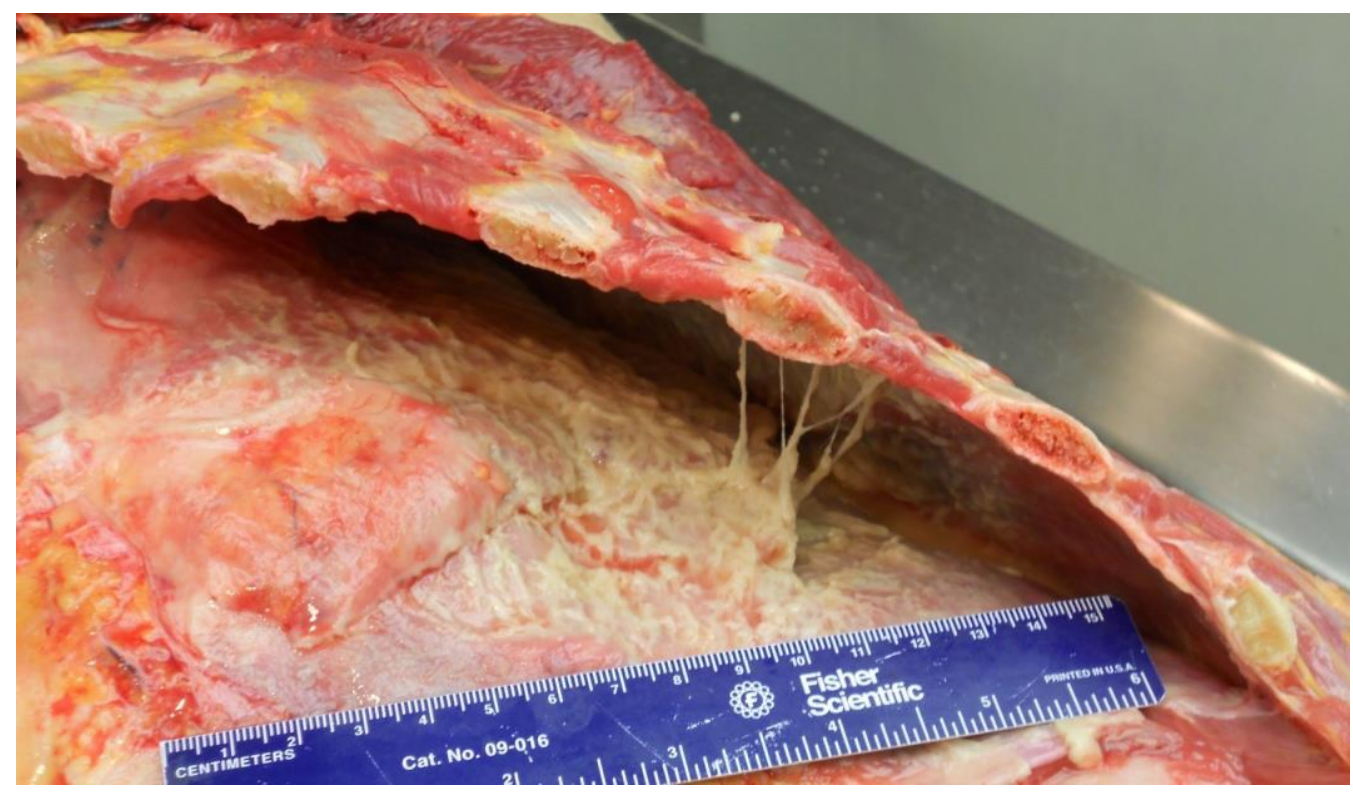


The clinical history and autopsy findings suggested that the cause of death was severe sepsis due to disseminated infection caused by bacterial endocarditis. Postmortem cultures of the lung and left pleural fluid grew Streptococcus pneumoniae. Autopsy also showed four-chamber dilatation of the heart, implicating heart failure as a contributing cause of death.

\section{Discussion}

Infective endocarditis due to Streptococcus pneumoniae accounts for $<1 \%$ of cases of infective endocarditis. ${ }^{7}$ It is more severe than infective endocarditis with many other pathogens. In a casecontrol study of twenty eight patients with pneumococcal endocarditis and fifty six patients with non-pneumococcal endocarditis during the years 1991-2013, features more common in pneumococcal than in non-pneumococcal endocarditis included heart failure $(64.3 \%$ versus $23.2 \%$; $\mathrm{p}<0.01)$, shock (53.6\% versus $23.2 \%$; $\mathrm{p}<0.01)$, associated alcoholism $(39.3 \%$ versus $10.7 \%$; $<<0.01)$, smoking (60.7\% versus $21.4 \%$; $<<0.01)$, and the absence of previously known valve disease $(82.1 \%$ versus $60.7 \%$; $\mathrm{p} 0.047){ }^{7}$ The most frequent complication of pneumococcal endocarditis is heart failure and it is associated with a high rate of mortality, up to $63 \%$, even with appropriate therapy. ${ }^{8}$

Infective endocarditis due to Streptococcus pneumoniae is often associated with pneumococcal infection of the meninges. The frequency of meningitis in cases of pneumococcal endocarditis ranges from $28.6 \%$ to $76 \%{ }^{7,8}$ Pneumococcal endocarditis is slightly more common on the aortic valve, occurring on that valve in nineteen of twenty eight cases $(70.4 \%)$ versus thirty five of fifty six controls $(62.5 \%), \mathrm{p}=\mathrm{NS}$, in the case control study cited above. ${ }^{7}$ In general, infective endocarditis is slightly more common on the mitral valve, in 1125/2740 (41\%) of cases, compared to $1031 / 2741$ (38\%) involving the aortic valve, in a large international study. ${ }^{9}$ An entity called the Austrian syndrome, defined as the triad of pneumococcal pneumonia with meningitis and infective endocarditis, has been described. ${ }^{10}$ Autopsy in this case revealed all three elements of the Austrian syndrome. In a review of thirty two cases of Austrian syndrome, it was noted that there was almost always a delay in the disease manifesting itself in all three organs and in making the diagnosis, sometimes a four to six week delay. ${ }^{10}$

The clinical history in this case suggests that some of the reasons for the delay in diagnosis might have been the multiplicity of the patient's symptoms, the lack of a stiff neck among his symptoms, the lack of finding a heart murmur on examination by multiple physicians, and the delay in reporting the results of the outpatient blood tests and chest x-ray done on the Saturday. This case suggests that bolstering the skills of primary care physicians in history and physical examination and in pattern recognition of atypical presentations of common conditions such as pneumonia might be a helpful way to improve patient safety in ambulatory care settings, which 
fits with the lessons learned in a recent study of missed opportunities for diagnosis in primary care. $^{6}$

It is possible that the patient's belief that his illness was due to injuries from coal mining may have framed the thinking of the physicians he saw as an outpatient, creating what could be called a framing effect or framing error, a form of cognitive bias leading to diagnostic error. ${ }^{11}$ It is possible that under-resourcing of medical laboratory and radiology services led to the delay in getting the blood test results to his physician and in getting the chest radiograph interpreted and reported.

This case has some similarity to one given as an example in a study of early warning signs for diagnostic errors in primary care. ${ }^{12}$ In that example, a patient presented to his primary care physician as an outpatient on a Saturday morning with dyspnea that the patient framed as exactly like the dyspnea he had had six months prior when heart failure was diagnosed. The primary care physician knew that getting any tests done and reported would not be easy on a Saturday and scheduled the patient for blood tests first thing on Monday morning. The physician also proceeded with the patient's framing the dyspnea as due to the same process as his heart failure six months prior. The patient's dyspnea worsened; he went to the hospital and was diagnosed with multiple pulmonary emboli. ${ }^{12}$

The case of the Appalachian coal miner reported here suggests that the workflow patterns created by weekends might sometimes have a detrimental effect on patient safety in ambulatory primary care settings. It might be worthwhile to compare the outcomes for patients seen on Fridays compared to days earlier in the workweek in under-resourced rural medical practices, and if they are not as good, to then look for solutions to the problem. Although it is not possible to know exactly what factors led to the diagnostic delay in this particular case, the case does suggest avenues of analysis and research to promote excellence in the practice of Appalachian rural health medicine. 


\section{References}

1. Yermak D, Cram P, Kwan JL. Five things to know about diagnostic error. Diagnosis (Berl). 2017 Mar;4(1):1315. doi: 10.1515/dx-2016-0043.

2. Singh H, Meyer AN, Thomas EJ. The frequency of diagnostic errors in outpatient care: estimations from three large observational studies involving US adult populations. BMJ Qual Saf. 2014 Sep;23(9):727-31. doi: 10.1136/bmjqs-2013-002627.

3. Singh H, Giardina TD, Meyer AN, Forjuoh SN, Reis MD, Thomas EJ. Types and origins of diagnostic errors in primary care settings. JAMA Intern Med. 2013 Mar 25;173(6):418-25. doi: 10.1001/jamainternmed.2013.2777.

4. Tudor Car L, Papachristou N, Bull A, Majeed A, Gallagher J, El-Khatib M, Aylin P, Rudan I, Atun R, Car J, Vincent C. Clinician-identified problems and solutions for delayed diagnosis in primary care: a PRIORITIZE study. BMC Fam Pract. 2016 Sep 9;17:131. doi: 10.1186/s12875-016-0530-z.

5. Murphy DR, Singh H, Berlin L. Communication breakdowns and diagnostic errors: a radiology perspective. Diagnosis (Berl). 2014 Dec;1(4):253-261. doi:10.1515/dx-2014-0035.

6. Goyder CR, Jones CH, Heneghan CJ, Thompson MJ. Missed opportunities for diagnosis: lessons learned from diagnostic errors in primary care. Br J Gen Pract. 2015 Dec;65(641):e838-44. doi: 10.3399/bjgp15X687889.

7. Daudin M, Tattevin P, Lelong B, Flecher E, Lavoué S, Piau C, Ingels A, Chapron A, Daubert JC, Revest M. Characteristics and prognosis of pneumococcal endocarditis: a case-control study. Clin Microbiol Infect. 2016 Jun;22(6):572.e5-8. doi: 10.1016/j.cmi.2016.03.011.

8. Murdoch DR, Corey GR, Hoen B, Miró JM, Fowler VG Jr, Bayer AS, Karchmer AW, Olaison L, Pappas PA, Moreillon P, Chambers ST, Chu VH, Falcó V, Holland DJ, Jones P, Klein JL, Raymond NJ, Read KM, Tripodi MF, Utili R, Wang A, Woods CW, Cabell CH; International Collaboration on Endocarditis-Prospective Cohort Study (ICE-PCS) Investigators. Clinical presentation, etiology, and outcome of infective endocarditis in the 21st century: the International Collaboration on Endocarditis-Prospective Cohort Study. Arch Intern Med. 2009 Mar 9;169(5):463-73. doi: 10.1001/archinternmed.2008.603.

9. Deshayes S, de Boysson H, Salmon-Rousseau A, Baldolli A, Auzary C, Geffray L. Pneumococcal Meningitis and Endocarditis: A Case Report. Am J Med. 2016 Mar;129(3):e19-20. doi: 10.1016/j.amjmed.2015.09.025.

10. Kanakadandi V, Annapureddy N, Agarwal SK, Sabharwal MS, Ammakkanavar N, Simoes P, Sanjani HP, Nadkarni GN. The Austrian syndrome: a case report and review of the literature. Infection. 2013 Jun;41(3):695700. doi: 10.1007/s15010-012-0361-3.

11. Elia F, Aprà F, Verhovez A, Crupi V. "First, know thyself": cognition and error in medicine. Acta Diabetol. 2016 Apr;53(2):169-75. doi: 10.1007/s00592-015-0762-8. Epub 2015 May 5.

12. Balla J, Heneghan C, Goyder C, Thompson M. Identifying early warning signs for diagnostic errors in primary care: a qualitative study. BMJ Open. 2012 Sep 13;2(5). pii: e001539. doi: 10.1136/bmjopen-2012-001539. 